\title{
La inconstitucionalidad por omisión: una revisión jurídica
}

\author{
Édgard Fabián Garzón-Buenaventura*
}

* Doctorando en Derecho, Universidad Libre de Colombia. Profesor catedrático, Universidad La Gran Colombia, Universidad de América y Universidad Cooperativa de Colombia, Bogotá, Colombia. Correo electrónico: edgar.garzon@campus.ucc.edu.co

Recibido: 22 de agosto de 2014 Aprobado: 2 de septiembre de 2014

Cómo citar este artículo:

Édgard Fabián Garzón-Buenaventura. La inconstitucionalidad por omisión: una revisión jurídica. DIxI 20. Diciembre 2014 Pág. 29. doi: http://dx.doi.org/10.16925/ di.v16i20.832

\section{Resumen}

En el desarrollo del estatuto normativo, se parte de la premisa de la validez jurídica de la norma, sostenida bajo el concepto positivista jurídico de la supremacía constitucional. Se desprende de esta idea que ninguna norma legislativa o administrativa puede contrariar por vía de acción el precepto legal. De acuerdo con lo anterior, es necesario instruir sobre la idea de que el legislador, el ejecutivo y los funcionarios administrativos también pueden atropellar el precepto jurídico por vía de omisión, razón por la cual se tiene obligación de actuar de una manera determinada para que tenga eficacia plena la norma constitucional.

Palabras clave: Constitución, control de constitucionalidad, Corte Interamericana, jueces constitucionales, omisión legislativa.

\section{UnConstitutionality By OMission: A Legal ReVieW}

\section{Abstract}

The development of regulatory statutes is based on the premise of the legal validity of laws and norms as well as the legal positivist concept of constitutional supremacy. This leads to the idea that no legislative or administrative law or regulation may violate a legal precept through action. It must therefore be said that lawmakers, the executive branch and administrative public servants can also violate legal precepts by omission, which is why they have to act in a certain way in order for a constitutional norm to be fully effective.

Keywords: Constitution, control of constitutionality, Inter-American Court, constitutional judges, legislative omission.

\section{A INCONSTITUCIONALIDADE POR OMISSÃo: UMA REVISÃo JURÍDICA}

\section{Resumo}

No desenvolvimento do estatuto normativo parte-se da premissa da validade jurídica da norma, mantida no conceito positivista jurídico da supremacia constitucional. Entende-se com essa ideia que nenhuma norma legislativa ou administrativa pode contradizer o preceito legal pela via de ação. De acordo com o acima indicado, é preciso instruir em relação à ideia de que o legislador, o executivo e os funcionários administrativos também podem atropelar o preceito jurídico pela via de omissão, portanto existe a obrigação de agir de uma forma determinada para que tenha eficácia plena a norma constitucional.

Palavras-chave: Constituição, controle de constitucionalidade, Corte Interamericana, juízes constitucionais, omissão legislativa. 


\section{INTRODUCCIÓN}

Al determinar la competencia del precepto constitucional, encontramos un vínculo entre el poder popular y la validez de la normas. De allí que sea preciso distinguir que el estatuto jurídico sostiene la legitimidad y la legalidad de los poderes del Estado, de manera que cada poder público se dedica a una función específica (legislativa, ejecutiva, judicial), para el mantenimiento del balance jurídico.

Así, el legislador cumple con una función específica: hacer la ley bajo las condiciones de la Carta Magna. Esto sin que su competencia sea exorbitante, esto es, no pecar por vía de acción u omisión, llevando así la eficacia jurídica y la validez del estatuto superior. Ahora, si bien el fin de esta acción parece loable, se trunca cuando el legislador no cumple su función o la hace defectuosamente, llevando así a la inconstitucionalidad por omisión absoluta o relativa.

\section{Metodología}

El artículo es base del proyecto "Conadi Convocatoria 2010 de Responsabilidad en Decisiones de la Corte Constitucional de Colombia a partir del Daño Antijurídico de la Constitución de 1991 en Colombia: una vista al derecho civil". Se busca instruir actualmente que la Carta Política de 1991 de Colombia tiene falencias, entre ellas, las de competencia constitucional, debido a que no se establece un marco claro de responsabilidad en la Administración de Justicia por parte de la Corte Constitucional en sede de tutela y control de constitucionalidad.

\section{A. Supremacía constitucional}

Entre los antecedentes de la supremacía constitucional, Badeni afirma:

Se suele citar a la graphé paranomón que se aplicó en Atenas, al Justicia de Aragón con las facultades que le fueron conferidas a partir de 1283 , la doctrina judicial formulada en 1610 por el juez británico Edward Coke, las disposiciones contenidas en el Agreement of the People de 1647 y el Instrument of Government de 1653. Sin embargo, la formulación positiva del principio, con las características que presenta actualmente, fue efectuada por la Constitución de los Estados Uni- dos, que en su artículo VI, párrafo segundo, establece: Esta Constitución, las leyes de los Estados Unidos que en su consecuencia se dicten, y todos los tratados celebrados o a celebrarse bajo la autoridad de los Estados Unidos, serán la ley suprema del país, y los jueces en cada estado estarán sujetos a ella, no obstante cualquier disposición en contrario contenida en la Constitución o en las leyes de cualquier estado. ${ }^{1}$

En el desarrollo de la Carta Magna, encontramos desde su aparición la escala jerárquica del precedente legal. Este mantiene dos vertientes: la estabilidad del Estado y las garantías de los ciudadanos. Esto se sustenta en que, por encima del precepto legal, no hay norma reglamentaria o administrativa que sea equiparable o superior, ni funcionario del Estado.

Esto da su apoyo en que en el contrato social entre ciudadanos y Estado se dé un respeto básico de convivencia, erigiéndose un mandato entre ambos en pro de la satisfacción de bienes y servicios. Por tanto, esto se cimienta en llevar a equiparar las funciones del Estado (legislativo, ejecutivo y judicial), no sólo como estructura del poder público, sino también de garantía judicial a los conciudadanos que pueden llevar a proteger su Carta Magna, tal como Don Quijote de la Mancha en la lucha del amor infranqueable de su Dulcinea.

Bulnes Aldunate declara:

El principio de supremacía constitucional, sustento del constitucionalismo contemporáneo, supone necesariamente el control y la sanción consecuente de las infracciones de la constitución, las que pueden originarse tanto en acciones positivas que violen la ley fundamental como en omisiones que contraríen un precepto legal. ${ }^{2}$

Pese a lo afortunado que parezca dentro del constitucionalismo moderno, ${ }^{3}$ la labor del legislador es unívoca. Responde a hacer la ley de acuerdo con los parámetros constitucionales y sólo a estos. Pero, ¿qué sucede cuando el legislador calla y deja lagunas legales? ¿Es posible llenar de acuerdo con la ambigüedad o vaguedad jurídica

\footnotetext{
1. Gregorio Badeni. Reforma constitucional E instituciones Políticas. Ad-Hoc. (1993).

2. Luz Bulnes Aldunate. La inconstitucionalidad por omisión. Estudios Constitucionales 4. Julio de 2006. Pág. 252. Disponible en http:// www.cecoch.cl/docs/pdf/revista_ano4_1/revista_ano4_1_14.pdf

3. Es posible señalar la Constitución de Filadelfia de 1787 como punto de inicio en que los Estados Unidos aceptan la división de los poderes y las libertades individuales.
} 
del estatuto normativo? ¿Es factible que el juzgador cree reglas jurídicas para solucionar casos, en los cuales no se pueda llenar con el precepto legal?

Todo esto apunta a decir que pese a la obligatoriedad de legislar por parte del constituyente, es posible que se quede a veces en el rezago jurídico resolver situaciones jurídicas concretas a los particulares, configurándose la omisión legislativa que no es más que la despreocupación por parte del legislador por expedir leyes o normas que desarrollen el precepto constitucional que genere un deber constitucional.

Por tanto, la Constitución es una fuente jurídica que opera en dos sentidos: a) funcional (establece el funcionamiento de los poderes del Estado) y b) material (regla hermenéutica de última interpretación jurídica en sede nacional). Esto nos lleva a intuir que el Estado se parte de una constitucionalización del derecho, transformando desde los aspectos técnicos, legislativos y jurisprudenciales, en procura de las garantías constitucionales de los ciudadanos.

Así, la Constitución no es una regla de imperativo descriptiva, es fuente que parte del concepto de soberanía nacional que representa la voluntad intrínseca y extrínseca de los que no hablan, de los que hablan y participan en la realpolitik ${ }^{4}$ de los ciudadanos. Por esto, el mandato debe ser la simbiosis perfecta entre lo que es y aquello a lo que se desea llegar a ser.

Esta a su vez - no por acción sino por omisiónvulnera el estatuto normativo. La Constitución no establece todos los mecanismos ni procedimientos para el imperativo de la norma constitucional, es labor del legislador desarrollar todos los detalles singulares que se adhieren a la carta y, cuando esto no sucede, se predica la omisión.

Ramírez Cleves afirma:

Para Hans Kelsen se trata de llevar a efecto los postulados de la norma suprema que establece órdenes de legislar, es decir la obligatoriedad de dotar de validez jurídica los preceptos constitucionales, mediante la expedición de normas inferiores que desarrollen las superiores y así que el sistema jurídico se integre y se reproduzca autopoieticamente a partir de la concatenación piramidal de una norma general que da una particular. ${ }^{5}$

4. Entiéndase la figura de la política real como la distinción entre las fuentes jurídicas de garantías constitucionales y el aparato administrativo que las niega con el precedente legal.

5. Gonzalo Ramírez Cleves. El Control Constitucional sobre las omisiones legislativas en Colombia. Ponencia. II Jornadas
En el marco constitucional se parte de una regla lógico-deductiva, estableciendo la premisa mayor como fundamento teórico-normativo para la producción sistemática del estatuto jurídico (legal-sentenciascostumbre). Esta es la labor importante de los poderes de las democracias constitucionales, es el punto de un proceso de la producción del derecho positivo.

\section{B. La inconstitucionalidad por omisión}

De acuerdo con lo anterior, es necesario identificar cómo, pese a que el legislador sea el llamado a operar la cláusula de normatividad legal a la Constitución, es comprensible que se dé la inconstitucionalidad por omisión en tres aspectos: la inconstitucionalidad por omisión administrativa o ejecutiva, omisión legislativa y omisión ilegal.

\section{Ferrer Mac-Gregor declara:}

Como puede fácilmente desprenderse del nomen iuris, la inconstitucionalidad por omisión hace referencia a ciertas omisiones que transgreden la norma fundamental. Atiendo al principio de separación de poderes se puede encontrar tres clases: omisiones administrativas o ejecutivas, omisiones legislativas y omisiones judiciales, cada una de ellas podrá ser calificada de inconstitucional siempre que tengan un sustento directo en la norma fundamental. ${ }^{6}$

Pese a la importancia de cada uno, la omisión administrativa se sanea bajo el evento de la acción de cumplimiento Ley 393 de 1997 administrativa en sede judicial. Lo complejo del asunto es la omisión legislativa constitucional. Se entiende por la omisión legislativa "la falta de desarrollo por parte del poder legislativo, durante un tiempo excesivamente largo, de aquellas normas constitucionales de obligatorio y concreto desarrollo, de forma tal que impide su eficaz aplicación". ${ }^{7}$

La inconstitucionalidad por omisión requiere lo siguiente:

Colombovenezolanas de Derecho Constitucional. (2006). Pág. 4.

6. Eduardo Ferrer Mac-Gregor. La inconstitucionalidad por omisión: implicaciones contemporáneas a la luz del Caso Marbury vs. Madison. Coord. P. L. Manili. Reflexiones Sobre una SENTENCIA BiCentenaria. Porrúa. (2011).

7. José Julio Fernández Rodríguez. LA inconstitucionalidad POR OMISIÓN: TEORÍA GENERAL, DERECHO COMPARADO, EL CASO ESPAÑOL. Civitas. (1998). Pág. 81. 
a. Es necesario que la Constitución establezca el deber de actuar del legislador.

b. El deber de actuar del legislador debe ser concreto y no abstracto.

c. La omisión no debe ser razonable teniendo en cuenta el tiempo que ha transcurrido para el cumplimiento del deber constitucional.

Además, se da la omisión cuando la Constitución defiere a la ley la reglamentación y la ley no se expide. Es decir, cuando se incumple una orden de legislar.

Asimismo, el jurista Wessel en $1952^{8}$ introdujo el tema de inconstitucionalidad por omisión legislativa en dos referentes: 1) Absoluta o Material: cuando hay ausencia total de norma secundaria o precepto constitucional que debiera ser desarrollado legislativamente; y 2) Relativa o Formal: cuando habiendo algún tipo de ejercicio legislativo, resulte incompleto o deficiente.

Para explicar la omisión ilegal, es necesario identificar cómo esta es predicable a ente o funcionario del Estado que implica el incumplimiento del dispositivo legal. Se trata de omisiones en la aplicación o ejecución de las leyes. Así, pueden incurrir en ellas los servidores públicos que pertenezcan a la rama administrativa o judicial. Un ejemplo se presenta cuando ciertas leyes requieren necesaria e inevitablemente de un reglamento para su efectiva aplicación, y este no es dictado por el ejecutivo.

El seguimiento de omisión ilegal se encuentra inmerso en el artículo 90 de la Constitución Política de Colombia, el denominado daño antijurídico, y descrito bajo la Ley 270 de marzo de 1996, Ley Estatuaria de Administración de Justicia, bajo los denominados títulos jurídicos de imputación: a) Error Jurisdiccional; b) Defectuoso Funcionamiento de la Administración de Justicia; y c) Privación Injusta de la Libertad.

Cada uno de estos es de la naturaleza de la responsabilidad sobre la administración de justicia sobre el precepto de la supremacía de la Constitución que hace admisible al Estado responsable en la acción de reparación directa para luego acudir bajo la Ley 678 de 2001 a la denominada acción de repetición.

\section{El rol de los jueces constitucionales en el control de las omisiones legislativas}

Cuando se da el sistema de control constitucional en sentido difuso bajo los antecedentes del Caso Bonham

8. En un libro denominado Die Rechtsprechung der BVerfG zur Lehre von Verfassungsbeschwerde. de 1610 y el Caso Marbury vs. Madison de 1803, y el sistema concentrado austriaco de constitucionalidad de 1920 , se presenta un nuevo aporte a la doctrina contemporánea. "La distancia que trazamos entre la jurisdicción constitucional (criterio orgánico u objetivo) y la justicia constitucional (criterio axiológico o subjetivo) es necesario para precisar la función que tienen los jueces que realizan esa tarea particular que representa fiscalizar el principio de supremacía constitucional"."

Los jueces mantienen un rol de protectores de la norma siendo estos sus defensores, guardianes e intérpretes en pro de la satisfacción de las garantías de los individuos en contra del Estado. Es posible que en el apego de esta función uno y otro cambien en sus efectos, mientras en los países con sistema difuso como Estados Unidos y Argentina la acción declarativa es interpartes, en los sistemas concentrados los efectos son erga omnes.

En esto se presenta una mayor preocupación en cuanto a la omisión legislativa: ¿es admisible que el tribunal constitucional cuando no hay norma aplicable al caso concreto por omisión absoluta o relativa pueda crear la regla jurisprudencial para llenar el vacío legal? ¿Es admisible una acción indemnizatoria por omisión legislativa? Es posible expresar que, gracias a la doctrina constitucional, se han verificado y dado tipologías de sentencias, entre ellas, las así denominadas sentencias atípicas, tales como las sentencias aditivas, sustitutivas, exhortativas, interpretativas, frente a la inconstitucionalidad por omisión, la inconstitucionalidad por retardo y mora, frente a la inconstitucionalidad por negación o por omisión relativa, y derechos fundamentales.

Alcalá afirma:

La inconstitucionalidad por retardo o mora, resulta de la inercia de la autoridad para establecer la norma legal o general respectiva. El caso más conocido y frecuente es el retardo del legislador para dictar las leyes de desarrollo constitucional para organizar y regular poderes públicos u órganos constitucionales o para desarrollar y regular cláusulas que no tienen carácter auto ejecutivas de la Carta Fundamental.

La inconstitucionalidad por negación o por omisión relativa, existe cuando el órgano estatal no efectiviza el mandato constitucional, por ejemplo, cuando el legislador sanciona la ley, pero lo hace incorrectamente,

9 Osvaldo Gozaíni. Tratado de Derecho Procesal Constitucional Latinoamericano. tomo i. Porrúa. (2011). Pág. 118. 
no regulando algunas hipótesis que debe regular o dejando lagunas en la legislación, excluyendo a un grupo del ejercicio de un derecho o negándole arbitrariamente la protección de sus intereses.

En el ámbito de los derechos fundamentales, puede sostenerse que hay inconstitucionalidad por omisión del legislador cuando la concreción legislativa es condición imprescindible para el desarrollo y ejercicio del derecho asegurado constitucionalmente y cuya omisión de parte del legislador daña su contenido esencial. El legislador no puede con su inactividad más allá de plazos razonables negar el ejercicio de derechos fundamentales asegurados constitucionalmente, porque de él no depende su existencia, la no regulación oportuna de los derechos fundamentales en su contenido esencial es equivalente a la negación del ejercicio del derecho. ${ }^{10}$

De esto encontramos en las sentencias de la Corte Constitucional de Colombia, las cuales nos dan un acercamiento a la doctrina de la omisión legislativa absoluta y relativa. En su acercamiento a la Sentencia de Control de Constitucionalidad C-543 encontramos lo siguiente:

Lo que se pretende mediante la acción de inconstitucionalidad, es evaluar si el legislador al actuar, ha vulnerado o no los distintos cánones que conforman la Constitución. Por esta razón, hay que excluir de esta forma de control el que se dirige a evaluar las omisiones legislativas absolutas: si no hay actuación, no hay acto que comparar con las normas superiores; si no hay actuación, no hay acto que pueda ser sujeto de control.

Las que sí pueden ser objeto de estudio por esta vía y, de hecho ya lo han sido, son las llamadas omisiones relativas o parciales, en las que el legislador actúa, pero lo hace imperfectamente, como en los casos arriba señalados, de violación al principio de igualdad o al debido proceso. ${ }^{11}$

Es de esto que el Órgano Concentrado Constitucional respeta un principio único: la separación de poderes frente la omisión legislativa absoluta, pero frente a la omisión legislativa relativa encuentra los referentes constitucionales para que prospere la acción.

10. Humberto Nogueira Alcalá. Consideraciones sobre las sentencias de los tribunales constitucionales y sus efectos en América del Sur. Revista IUs et Praxis 10. 2004. Págs. 154-155.

11. Corte Constitucional de Colombia. Sentencia C-543 DE 1996. (M. P. Carlos Gaviria Díaz; octubre 16 de 1996). Págs. 49-50. Disponible en: http://www.secretariasenado.gov.co/senado/basedoc/ cc_sc_nf/1996/c-543_1996.html
De acuerdo con la Sentencia de Control de Constitucionalidad C-1009:

Esta Corporación ha señalado de manera reiterada en su jurisprudencia que para efectos de proceder al examen de constitucionalidad de una disposición jurídica, por haber incurrido el Congreso en omisión legislativa relativa, se hace necesario el cumplimiento de ciertas condiciones, a saber: (i) que exista una norma sobre la cual se predique necesariamente el cargo; (ii) que la misma excluya de sus consecuencias jurídicas aquellos casos que, por ser asimilables, tenían que estar contenidos en el texto normativo cuestionado, o que el precepto omita incluir un ingrediente o condición que, de acuerdo con la Constitución, resulta esencial para armonizar el texto legal con los mandatos de la Carta; (iii) que la exclusión de los casos o ingredientes carezca de un principio de razón suficiente; (iv) que la falta de justificación y objetividad genere para los casos excluidos de la regulación legal una desigualdad negativa frente a los que se encuentran amparados por las consecuencias de la norma; y (v) que la omisión sea el resultado del incumplimiento de un deber específico impuesto por el constituyente al legislador. ${ }^{12}$

En razón a lo anterior, la Corte Constitucional de Colombia ha cobijado la tesis de denegar la omisión legislativa absoluta, pero su permisividad frente a la omisión legislativa relativa frente a unas causales específicas.

\section{Manrique afirma:}

Pese a lo anterior, como quedo planteado, en el constitucionalismo actual es innegable que los tribunales constitucionales han ido asumiendo tareas marcadas positivas o creadoras de normas a través de la modulación de los efectos de sus sentencias, configurándose un legislador positivo. La mayoría de las decisiones de los tribunales constitucionales no se limitan a excluir la norma del ordenamiento jurídico sino que incorpora una nueva disposición. ${ }^{13}$

Los tribunales constitucionales juegan a un rol político en sus decisiones, siendo estos legisladores positivos para la conformación jurídica de su jurisprudencia,

12. Corte Constitucional de Colombia. Sentencia C-1009 DE 2005. (M. P. Manuel José Cepeda Espinosa; octubre 5 de 2005). Pág. 10. Disponible en http://www.corteconstitucional.gov.co/relatoria/2005/C-1009-05.htm

13. Sandra Manrique. InCONSTITUCIONALIDAD POR OMISIÓN EN Colombia. Universidad de Antioquia. (2006). Pág. 108. 
ya sea cuando lo ejercen en control abstracto de inconstitucionalidad, o bien en el control concreto en sentencias de tutela. Estas sentencias crean reglas jurídicas que constituyen vínculos en las decisiones para los poderes públicos, sea abnegando el principio de la separación democrática de los poderes y el activismo judicial de la decisión.

\section{La omisión inconvencional: inconvencionalidad por omisión}

Tras el colapso de la sociedad de las naciones, el final de la Segunda Guerra Mundial, la aparición del derecho internacional y de los derechos humanos en el siglo XX, los Estados se comprometen a crear la declaración universal de los derechos humanos y la carta de las Naciones Unidas como pactos internacionales de protección. Se da una esfera de protección interna e internacional, generando un sistema subsidiario, universal y reforzado.

\section{Mac-Gregor afirma:}

Lo anterior ha propiciado que también se generen nuevas formas de omisión, debido a la obligación de los Estados de cumplir con las declaraciones, pactos, convenciones o tratados internacionales, incluso recientemente, también con la jurisprudencia de los órganos jurisdiccionales que los interpretan. Asi cuando un Estado no cumple con un compromiso internacional por una actividad de su parte, estamos en presencia de omisiones inconvencionales (que puede ser parcial o absoluto) generando una responsabilidad internacional para el Estado. ${ }^{14}$

Resulta interesante cuando apelamos a sentencias transnacionales y estas hacen parten del denominado estatuto del derecho internacional de los derechos humanos, sean porque están consagradas a una imparcialidad plena, o bien sancionan de una forma directa a los Estados cuando estos vulneran la convención, como en el caso concreto del Pacto de San José de Costa Rica, del cual hacen parte veinticuatro Estados y ventiuno ratificaron la competencia de la Corte Interamericana de Derechos Humanos. Este mandato cobija la garantía judicial efectiva que apela a la protección inmediata de los ciudadanos fuera del sistema nacional, ejerciendo el Control de Convencionalidad como estatuto de

14. Ferrer Mac-Gregor, supra, nota 6. Pág. 108. lex superior, haciendo inoponible la ley nacional de los Estados.

Mac-Gregor declara:

En definitiva, las variantes de las omisiones inconvencionales, obedecen a un tipo de inconvencionalidad que desde hace más de treinta años la Corte Interamericana viene realizando a través del llamado Control de Convencionalidad como función propia de la Corte Interamericana, al confrontar las actuaciones de los Estados con la Convención Americana, a manera de lex superior..$^{15}$

Para esto podemos tomar algunos ejemplos de la Corte Interamericana, en los cuales hace una control abstracto del ordenamiento legal del Estado vs. la Convención Americana de Derechos Humanos.

De acuerdo con la Sentencia del 5 de febrero de 2001 (Fondo, Reparaciones y Costas):

87. En el derecho de gentes, una norma consuetudinaria prescribe que un Estado que ha ratificado un tratado de derechos humanos debe introducir en su derecho interno las modificaciones necesarias para asegurar el fiel cumplimiento de las obligaciones asumidas. Esta norma es universalmente aceptada, con respaldo jurisprudencial. La Convención Americana establece la obligación general de cada Estado Parte de adecuar su derecho interno a las disposiciones de dicha Convención, para garantizar los derechos en ella consagrados. Este deber general del Estado Parte implica que las medidas de derecho interno han de ser efectivas (principio del effet utile). Esto significa que el Estado ha de adoptar todas las medidas para que lo establecido en la Convención sea efectivamente cumplido en su ordenamiento jurídico interno, tal como lo requiere el artículo 2 de la Convención. Dichas medidas sólo son efectivas cuando el Estado adapta su actuación a la normativa de protección de la Convención.

88. En el presente caso, al mantener la censura cinematográfica en el ordenamiento jurídico chileno (artículo 19 número 12 de la Constitución Política y Decreto Ley número 679), el Estado está incumpliendo con el deber de adecuar su derecho interno a la Convención de modo a hacer efectivos los derechos consagrados en la misma, como lo establecen los artículos 2 y 1.1 de la Convención..$^{16}$

\section{Id.}

16. Corte Interamericana de Derechos Humanos. Caso "La Última Tentación de Cristo". (Olmedo Bustos y Otros vs. Chile; febrero 5 de 2001). Págs. 87 y 88. Disponible en: http://www.corteidh.or.cr/docs/ casos/ar ticulos/Seriec73esp.pdf 
Esto nos lleva a incluir que la vulneración de la Convención hace responsable internacionalmente al Estado, cuando este quebranta la regla, principios, o materias que son de unión y punto de partida para los Estados. Esto va desde garantía del debido proceso hasta incluir plazos desmedidos, generando así una omisión inconvencional. El contenido está marcado por principios y valores que sustentan interpretaciones que constituyen el núcleo esencial del derecho internacional de los derechos humanos.

Según la Sentencia del 27 de abril de 2012:

La Corte Interamericana ha interpretado que la adecuación de la normativa interna a los parámetros establecidos en la Convención implica la adopción de medidas en dos vertientes, a saber: a) la supresión de las normas y prácticas de cualquier naturaleza que entrañen violación a las garantías previstas en la Convención o que desconozcan los derechos allí reconocidos u obstaculicen su ejercicio, y b) la expedición de normas y el desarrollo de prácticas conducentes a la efectiva observancia de dichas garantías. La primera vertiente se satisface con la reforma, la derogación o la anulación de las normas o prácticas que tengan esos alcances, según corresponda. La segunda, obliga al Estado a prevenir la recurrencia de violaciones a los derechos humanos y, por eso, debe adoptar todas las medidas legales, administrativas y de otra índole que sean necesarias para evitar que hechos similares vuelvan a ocurrir en el futuro. ${ }^{17}$

De acuerdo con esto, la regla de la convención americana es la ratio decidendi que conforma el prisma de las garantías tanto constitucionales como legales, generando la construcción de un bloque de constitucionalidad a un bloque de convencionalidad cuya naturaleza es la protección de los derechos humanos y así evitar la omisión inconvencional, generando reglas y pautas para los diferentes Estados.

\section{Resultados y Conclusiones}

La omisión legislativa relativa es el cauce a través del cual los jueces constitucionales desarrollan un control de legalidad constitucional sobre los defectos del legislador. Debido a la inactividad legislativa, tienen

17. Corte Interamericana de Derechos Humanos. Caso Forneron e Hija vs. Argentina. Sentencia de 27 De Abril de 2012 (Fondo, Reparaciones y Costas). Pág. 131. que suplir para que no se creen lagunas jurídicas en el derecho.

La potestad de la jurisdicción de la libertad como - señalaba Cappelletti- es crear un nexo entre la norma y la sociedad a fin de salvaguardar la integridad jurídica. El defecto de esto se presenta en dos vías: 1) ¿Quién controla al controlador cuando crea sentencias atípicas para llenar los vacíos jurídicos?, 2) ¿Qué sucede con el sometimiento a la jurisdicción internacional que ordena crear normas para suplir los vacíos jurídicos?

Estas son las figuras que dentro de un marco de protección de los derechos humanos y del Estado constitucional, se presentan para ejercer la potestad jurisdiccional local, nacional e internacional

\section{REFERENCIAS}

Constitución Política de Colombia. Julio 7 de 1991 (Colombia).

Corte Constitucional de Colombia. Sentencia C-543 DE 1996. (M. P. Carlos Gaviria Díaz; octubre 16 de 1996). Disponible en: http://www.secretariasenado.gov.co/senado/basedoc/cc_sc_nf/1996/c-543_1996.html

Corte Constitucional de Colombia. Sentencia C-1009 DE 2005. (M. P. Manuel José Cepeda Espinosa; octubre 5 de 2005). Disponible en http://www.corteconstitucional.gov.co/relatoria/2005/C-1009-05.htm

Corte Interamericana de Derechos Humanos. CAso "LA ÚLtima tentación de CRisto". (Olmedo Bustos y Otros vs. Chile; febrero 5 de 2001). Disponible en: http://www. corteidh.or.cr/docs/casos/ar ticulos/Seriec73esp.pdf

Corte Interamericana de Derechos Humanos. CAso Forneron e Hija vs. Argentina. Sentencia de 27 De Abril DE 2012 (FONDO, REPARACIONES Y COSTAS).

Eduardo Ferrer Mac-Gregor. La inconstitucionalidad por omisión: implicaciones contemporáneas a la luz del Caso Marburyvs. Madison. Coord. P. L. Manili. Reflexiones sobre UnA SEntencia bicentenaria. Porrúa. (2011).

Gonzalo Ramírez Cleves. El Control Constitucional SOBRE LAS OMisiones Legislativas EN Colombia. Ponencia. II Jornadas Colombovenezolanas de Derecho Constitucional. (2006).

Gregorio Badeni. Reforma Constitucional E INSTITUCiONES POlíticas. Ad-Hoc. (1993).

Humberto Nogueira Alcalá. Consideraciones sobre las sentencias de los tribunales constitucionales y sus efectos en América del Sur. Revista Ius et Praxis 10. 2004. Págs. 113-158. 
José Julio Fernández Rodríguez. La inconstitucionaliDAD POR OMISIÓN: TEORÍA GENERAL, DERECHO COMPARADO, EL CASO ESPAÑOL. Civitas. (1998).

Luz Bulnes Aldunate. La inconstitucionalidad por omisión. Estudios constitucionales 4. Julio de 2006. Págs. 251-264. Disponible en http://www.cecoch.cl/docs/ pdf/revista_ano4_1/revista_ano4_1_14.pdf
Osvaldo Gozaíni. Tratado de Derecho Procesal ConstituCional latinoamericano. Tomo i. Porrúa. (2011).

Sandra Manrique. INCONSTITUCIONALIDAD POR OMISIÓN EN Colombia. Universidad de Antioquia. (2006). 